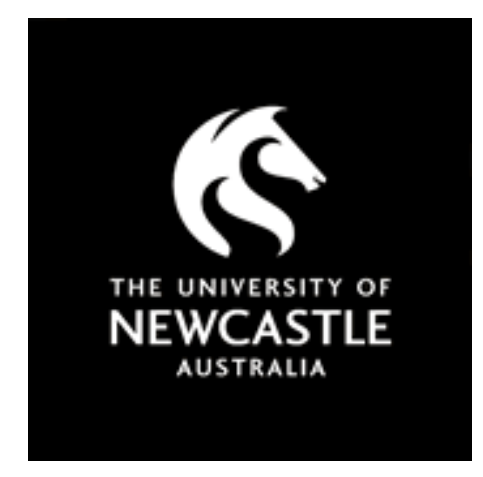

NOVA

University of Newcastle Research Online

nova.newcastle.edu.au

Rose, R. J.; Mantiri, F. R.; Kurdyukov, S.; Chen, S.-K.; Wang, X.-D.; Nolan, K. E.; Sheahan, M. B. “ Developmental biology of somatic embryogenesis". Originally published

Plant Developmental Biology: Biotechnological Perspectives, Volume 2 p. 3-26 (2010)

Available from: http://dx.doi.org/10.1007/978-3-642-04670-4 1

The original publication is available at www.springerlink.com

Accessed from: $\underline{\text { http://hdl.handle.net/1959.13/930026 }}$ 


\section{The Developmental Biology of Somatic Embryogenesis}

R.J. ROSE, F.R. MANTIRI, S. KURDYUKOV, S.-K. CHEN, X.-D. WANG, K.E NOLAN, and M.B. SHEAHAN

Australian Research Council Centre of Excellence for Integrative Legume Research, School of Environmental and Life Sciences, The University of Newcastle, University Drive, Callaghan, NSW 2308, Australia;

email: Ray.Rose@newcastle.edu.au 


\begin{abstract}
Somatic embryogenesis (SE) is a remarkable developmental process enabling nonzygotic plant cells to form embryos and ultimately, fertile plants. It is an expression of totipotency. This chapter initially considers the genotypic component and the progenitor stem cells where SE is induced to form the initial asymmetric division of the somatic embryogenesis program. These cells are part of a stem cell niche dependent on the surrounding cells. Recent evidence is discussed that before the SE pathway can be initiated a GA-modulated pathway that represses inappropriate embryogenesis needs to be derepressed. The current understanding of how stress and hormones can induce the activation of specific SE genes is examined. Important stress components are reactive oxygen species and the signalling of stress-related hormones. The action of the key developmental hormone auxin, and also cytokinin, in relation to developmental genes is considered and, based on current understanding, a model is presented for the mechanism of SE. While there are many SE applications in contemporary biotechnology, understanding the reprogramming process associated with SE remains an important question for developmental biology.
\end{abstract}




\section{Introduction}

Somatic embryogenesis (SE) is a remarkable developmental process enabling nonzygotic plant cells, including haploid cells, to form embryos and ultimately, fertile plants. An expression of totipotency, this asexual process involves dedifferentiation of a nonzygotic cell and subsequent redifferentiation (reprogramming), resulting in the production of all cells characteristic of the mature plant. Although primarily considered in the context of in vitro SE from cultured tissues or cells, SE is also a naturally occurring means of asexual reproduction in some species. For example, somatic embryos form on the succulent leaves of Kalanchoë (Garcês et al. 2007) and apomixis, a clonal reproductive process where embryos derive from cells in the ovule wall producing seed genotypically identical to the parent, occurs in a number of evolutionarily divergent plant species (Koltunow and Grossniklaus 2003). This discussion focuses on in vitro SE, but an understanding of this process is applicable to all forms of SE.

SE was first demonstrated 50 years ago by Steward et al. (1958) and Reinert (1958) in carrot. More recently, the emphasis has been on inducing SE in an ever-increasing number of species and cultivars to facilitate genetic transformation. The molecular mechanisms of SE remain poorly understood with mechanistic studies focused primarily on the hormonology of this developmental process. The classic paradigm is that auxin is initially required to induce SE, while its subsequent withdrawal, or reduction in concentration, drives embryo development (Halperin 1966; Dudits et al. 1991). In many species, cytokinin in addition to auxin is required for SE (Nolan and Rose 1998). These are not the only hormones to consider, but usually the critical ones. Understanding of how auxin and cytokinin signalling regulates transcription has advanced in recent times (Tan et al. 2007; Müller and Sheen 2007). Application of this understanding to $\mathrm{SE}$, however, is limited and requires an understanding of the interaction of these hormonal signalling pathways with key developmental genes. Increasingly, stress is recognised as having a critical role in the induction of SE (Touraev et al. 1997; Fehér et al. 2003; Nolan et al. 2006). Thus, hormones and stress collectively induce cell dedifferentiation and initiate an embryogenic program in plants with a responsive genotype (Fehér et al. 2003; Ikeda-Iwai et al. 2003; Rose and Nolan 2006). 
SE in vitro takes two forms, indirect and direct, referring respectively to the presence or absence of a phase of callus development (Dijak et al. 1986; Williams and Maheswaran 1986). As indirect SE is more commonly employed, this form is emphasized, and direct SE is also discussed, given that there is likely a continuum in terms of the amount of dedifferentiation and cell proliferation required before somatic embryos are induced.

The ability to produce embryos from nonzygotic cells and to regenerate whole plants is one of the fundamental questions of contemporary biology (Vogel 2005). This chapter summarises current understanding of the cell and molecular biology of SE and discusses the implications SE has to biotechnology.

\section{The Basic Requirements for In Vitro Somatic Embryogenesis}

Formation of somatic embryos in a given species typically entails culturing an explant (of appropriate tissue type and genotype) in a basal medium with a suitable hormone regime (Rose 2004). Importantly, excision and culture of the tissue introduces a stress component. A number of studies indicate that stress itself acts as an inducer of SE (Kamada et al. 1993; Touraev et al. 1997; Ikeda-Iwai et al. 2003) and, indeed, is the first event experienced by cells on excision of the explant from the plant tissue or the isolation of a cell before initiating the culture process. The basal medium can modify the amount of SE in a given explant (Ammirato 1983) and is, of course, essential for SE, but is usually not a key regulator. In considering the mechanism of SE, Fig.1 needs to be understood, which will serve as the basis for considering SE in this chapter.

\section{The Explant and Stem Cell Biology}

It may be possible in some circumstances for a somatic embryo to derive from more than a single cell (Williams and Maheswaran 1986). However, it is known from the tracking studies of de Vries and coworkers that an embryo can develop from a single totipotent somatic cell; both in the classic carrot cell 
suspension system (Schmidt et al. 1997) as well as in other species where somatic embryos are derived from leaf explants (Somleva et al. 2000). These single-cell progenitors of somatic embryos are totipotent stem cells as opposed to the pluripotent cells of plant meristems. Given the developmental programming required for embryo formation and its vascular independence from surrounding cells or callus (Haccius 1978), it seems likely that development from totipotent stem cells is the norm for SE. What is far from clear is which genotype and specific cell type enable SE.

\subsection{Genotype}

It is apparent from many studies, and a serious problem for biotechnology, that within a species only some cultivars are regenerable by SE (Bingham et al.1975; Ammirato 1983; Vasil 1988). Work by Bingham et al. (1975) in Medicago sativa demonstrated the possibility to breed for SE, with an ensuing study by Kielly and Bowley (1992) suggesting that a SE-competent phenotype is dominant and that two genetic loci are involved. The identity of the genes residing at these loci, however, remains unknown. While genotypic influences may have a genetic basis, another line of enquiry suggests a role for epigenetic phenomena, in particular, the pattern of chromatin condensation. Investigations in plant epigenetics reveal heterochromatin to be marked by methylation of cytosine and histone H3 (Bender 2004). Data supporting epigenetic control of SE are not extensive, but provide some support for the control of SE by methylation pattern. Thus, disruption of DNA methylation pattern with 5-azacytidine in $M$. truncatula (Santos and Fevereiro 2002) and carrot (Yamamoto 2005) disrupts SE. Recent studies show the involvement of small interfering RNAs in the condensation of chromatin (Bäurle et al. 2007, Henderson and Jacobsen 2007). Importantly, DNA methylation patterns are heritable and can be maintained across mitosis (Henderson and Jacobsen 2007). 
Interestingly, in $M$. truncatula all highly embryogenic genotypes, Jemalong 2HA (Nolan et al. 1989; Rose et al. 1999), R108 (Hoffman et al. 1997) and M9-10a (Araújo et al. 2004), were derived after a cycle of tissue culture. This fact suggests the regeneration process selects for somatic cells with competence for SE, a heritable trait. Moreover, it suggests the regeneration process might provide a consistent selection for an epigenetic pattern in the cultured somatic cells, as a cycle of tissue culture is always enough to enhance regenerability (Nolan et al. 1989; Hoffman et al. 1997).

In plant development, genes promoting embryogenesis ought to be repressed as nonzygotic cells develop in the plant body. There is evidence that SE can be induced in the Arabidopsis pickle mutant (Ogas et al. 1997) by derepressing the embryogenesis pathway. PICKLE acts to repress embryonic traits (Henderson et al. 2004) and encodes a CHD3 chromatin-remodelling factor (Ogas et al. 1999). It is possible that activation of the expression of embryogenesis-promoting genes, repressed during development, enables SE. The repression of embryogenesis appears to involve gibberellic acid (GA) metabolism, discussed later in this chapter (Henderson et al. 2004).

\subsection{Explant Cells}

When callus forms from an explant before the appearance of somatic embryos, a question exists as to from which cells the embryos derive. Historically, this has been investigated and discussed in relation to carrot cell suspension cultures (Halperin 1966). In establishing cell suspension cultures, explants have been taken from various tissues including hypocotyls (Guzzo et al. 1994; Schmidt et al. 1997), where cell division is initiated in provascular cells that form embryogenic callus that is transferred into liquid cell suspension culture. In the original work on SE by Steward et. al $(1958,1964)$, explants were obtained from the phloem of the storage root of carrot and then SE induced in liquid culture. What is possibly the case here in the carrot studies is the presence in these tissues of procambial-like cells (involved in the differentiation of vascular tissue) which readily reprogram to a totipotent state. Once the carrot cells are 
in liquid culture in the presence of auxin, proembryogenic masses (PEMs) form. Further embryonic development does not then occur until removal of auxin. Tracking cells in a newly initiated cell suspension culture via expression of a pSERK-LUC fusion reveals that most somatic embryos develop from single cells or small cell clusters originally derived from provascular cells (Schmidt et al. 1997). In established cultures, somatic embryos derive from cells in PEMs.

As plant biotechnology progressed, regeneration via SE was developed for many species using agar-solidified medium. Histological studies often focused on demonstrating that regeneration was via SE rather than organogenesis (e.g. Sharma and Millam 2004). In the Sharma and Millam study, meristematic zones from embryogenically induced internode segments were noted and interpreted as PEMs. Our unpublished data with $M$. truncatula, using both mesophyll protoplasts and leaf explants, provides support for two types of progenitor cells for SE. Callus that derives from leaf explants is permeated by vascular tissue. Some SEs develop from the parenchyma-like callus cells near the epidermis (Fig. 2) while others are from the provascular or procambial tissue, mirroring that observed in carrot hypocotyls. There is good supporting evidence for embryos forming at the periphery of callus in a diversity of species such as guinea grass (Lu and Vasil 1985), pea (Loiseau et al. 1998), chickpea (Sagare et al. 1995) and potato (Sharma and Millam 2004). The other common feature with embryogenic callus in a number of studies is the link to vascular tissue (Lu and Vasil 1985, Schwendiman et al. 1988; Schmidt et al. 1997; Somleva et al. 2000) which goes back to the early studies of Steward et al. (1958). Procambial cells are pluripotent stem cells characterised by their capacity to differentiate into cells of the vasculature. This was emphasised in studies of adventitious root formation in $M$. truncatula, where it was clear that cells proliferating from the procambial-like cells of the veins of leaf explants could differentiate into root meristems in response to auxin (Rose et al. 2006). Kwaaitaal and de Vries (2007) subsequently showed that SERK1 (which marks cells that form somatic embryos - see later) expressed in procambium cells and immature vascular cells (also observed in M. truncatula), responds to auxin.

The M. truncatula protoplast system (Rose and Nolan 1995) where SEs derive from mesophyll cells clearly illustrates that mature plant cells can dedifferentiate and ultimately form SEs without any initial vascular tissue being present (Mantiri et al. 2008). Direct SE from mesophyll protoplasts of $M$. 
sativa has also been demonstrated (Dijak et al. 1986). These data are brought together in a conceptual manner in Fig. 2.

\section{The Earliest Event in Embryogenesis - Asymmetric Cell Division}

During zygotic embryogenesis, the zygote divides asymmetrically to produce an apical cell, which forms the majority of the embryo, and a basal cell, which forms the suspensor (Scheres and Benfey 1999). The apical cell is smaller and densely cytoplasmic and the basal cell larger and vacuolated (Jenik and Barton 2005). While the basal cell gives rise to the suspensor and tethers the embryo to the ovule, the suspensor cell adjacent to the apical cell (the hypophysis) generates the quiescent centre of the root pole, as well as the root cap and its associated stem cells. The remainder of the root meristem traces back to the apical cell (Jenik and Barton 2005). Therefore, the first cell divisions of the zygote delineate the polarity that determines the root and shoot apical meristems. Tight regulation of each embryonic cell division produces cellular patterning resulting, ultimately, in a heart stage embryo. Cell division patterning appears to be controlled by auxin fluxes (Friml et al. 2003; Kepinski and Leyser 2003), WOX transcription factors (Haecker et al. 2004), cell wall components (Souter and Lindsey 2000; Ingram 2004) and a number of other genes (Chandler et al. 2007).

One protein linked directly to apical-basal pattern formation in the Arabidopsis embryo is GNOM, an ADP-ribosylation factor guanine-nucleotide exchange factor (ARF-GEF) required for correct localisation of, among other proteins, the PIN1 auxin transporter (Geldner et al. 2003). Mutations in GNOM can produce seedlings that lack basic polarity and possess unusual shapes (Mayer et al. 1993). This patterning can be related to alteration in the first cell division in the gnom mutant where two nearly equal-size cells are produced, rather than the distinctive asymmetric division (Mayer et al. 1993).

\subsection{The Cell Wall in Establishment of Polarity, Division Asymmetry and Cell Fate}


One fundamental set of questions that exists in plant biology is how plant cell identity is determined, how cells decide whether to divide or expand, and whether they commit to a specific developmental fate. In the context of SE, specifically, how does a nonzygotic cell become committed to an embryogenic pathway and develop the intricate patterning present in an embryo? Numerous studies, both classical and recent, reveal that plant cell fate can be respecified according to its position relative to other cells (Ingram 2004). In other words, the fate of a cell depends more on its neighbours than its mother cell (MajewskaSawka and Nothnagel 2000). This implies that cells continually communicate with one another during plant development. Since a rigid cell wall encompasses the plant cell, communication between the cell interior and the environment occurs via the cell wall (Satoh 1998). Indeed, increasing evidence eludes to the fundamental role that cell wall components (both protein and saccharide) have in regulating cell division patterns, cell shape, intercellular attachment, wound/defence-related signalling, programmed cell death (PCD), polarity establishment and determination of cell fate. Arabinogalactan proteins (AGPs), hydroxyproline-rich glycoproteins with complex carbohydrate side-chains comprising approximately $90 \%$ of the molecules mass, are believed to be of particular importance in the abovementioned processes (Majewska-Sawka and Nothnagel 2000).

The role of cell wall components in establishing axial-basal polarity (required for division asymmetry) is perhaps best illustrated by early development in Fucus zygotes. Here, deposition of sulphated polysaccharides at the base of the cell defines the basal-axial axis leading to the development of thallus (apical) and rhizoid (basal) cell after the first asymmetric division. Interestingly, remnant cell wall in protoplasts isolated from these cells is sufficient to direct the fate of the cells in culture (Souter and Lindsey 2000). Similarly, establishment of the axial-basal polarity in zygotes of higher plants may involve differential distribution of cell wall components. For example, during Brassica embryogenesis, the JIM8 antibody, which recognises a specific AGP epitope, only localises to cells fated to become the suspensor (Pennell et al. 1991; Souter and Lindsey 2000). Thus, polarity can be established before the first asymmetric division through differential localisation of AGPs.

Recently, a hydroxyproline-rich glycoprotein, $\mathrm{RSH}$, has been shown to be essential for normal embryo patterning, with influences observed at the first asymmetric division of the zygote (Hall and 
Cannon 2002). In rapidly dividing cells of the embryo, RSH localises to the cell plate-cell wall junction, suggesting a role in positioning of the cell plate at cytokinesis. Mutation of RSH leads to morphologically defective embryos, with irregularly sized and shaped cells. Similarly, the cellulose synthase - like gene, AtCSLA7, which encodes a processive $\beta$-glycosyltransferase is critical for normal embryogenesis causing homozygous AtCSLA7 mutants to have slow developing embryos with abnormal cell patterning that arrest at the globular stage (Goubet et al. 2003). Interestingly, mutation in GNOM produces a phenotype most similar to RSH and AtCSLA7 mutants, suggesting that RSH and AtCSLA7 are cargo in GNOMassociated vesicles. Whether the role for GNOM in embryogenesis reflects secretion of cell wall components or localisation of auxin transporters is unclear (Ingram 2004).

\subsection{Division Asymmetry in the Initiation of SE}

Somatic embryos have a similar developmental pattern to zygotic embryos, passing through globular, heart, torpedo and cotyledonary stages (Rose 2004). However, somatic cells that form embryos do so in various different environments and tissues, notably without endosperm (Williams and Maheswaran 1986). Thus, are the signalling environment and the division asymmetry necessary for zygotic embryogenesis also required for SE? Evidence for the existence of asymmetric divisions comes from a substantive study involving cell suspension cultures of carrot (McCabe et al. 1997). In these cultures, JIM8+ (state B) cells undergo asymmetric division giving rise to a JIM8+ (state F) cell and a JIM8- (state C) cell. State F cells eventually undergo PCD, while state C cells are competent for SE providing that conditioned media factors from JIM8+ cultures (presumed to be AGPs) are present. Soluble signals from JIM8+ cells that direct state C cells along a SE pathway may be akin to endosperm-derived signals believed to direct development of the zygotic embryo (Ingram, 2004), suggesting possible commonalities in the signalling environments of zygotic and SE.

In $M$. sativa where leaf protoplasts may undergo direct SE, asymmetric cell divisions result in SE, whereas symmetrically dividing cells form callus (Dudits et al. 1991). Asymmetric cell divisions of elongated cells were also observed in the provascular tissue of carrot explants in response to auxin 
(Guzzo et al. 1994). These asymmetrically divided cells give rise to PEMs, from which embryos subsequently develop in the absence of auxin (presumably following a further asymmetric division). Morphological asymmetry, however, was not observed in Cichorium (Blervacq et al. 1995). The evidence for the involvement of asymmetric divisions in SE is best in the case of isolated single cells or protoplasts. The evidence in tissue explants or calli derived from protoplasts, however, is more difficult to obtain. The current authors have observed early asymmetric divisions in somatic embryo formation in calli from isolated protoplasts. In many cases of SE it is probably hard to obtain the clear-cut asymmetric division observed in the zygote, a possible explanation for why many somatic embryos do not progress to plants. Overall, however, there is support for asymmetrical divisions being an integral component of SE (Fehér et al. 2003).

\subsection{Asymmetric Division and the Suspensor in SE}

One of the difficulties in interpreting early development of somatic embryos is that of the suspensor. Are the asymmetric cell divisions of state B cells analogous to the first division of the zygote? Certainly, the JIM8 labelling pattern of divided state B cells is analogous to that observed after the first embryonic division in Brassica (seeSection 4.1), and so potentially, the cell undergoing PCD after the asymmetric division represents an aberrant suspensor. In the cell tracking study of Schmidt et al. (1997), which used carrot cell suspension cultures expressing a SERK-reporter, a suspensor attached to elongated cells in the culture can be seen in one tracking series but not in another. Because of the unusual developmental context of SE, suspensor development is rather variable, ranging from a large group of cells to absent (Williams and Maheswaran 1986). Thus, the hypophysis-root pole relationship is unlikely to be the same in both zygotic and SE.

\section{The Stress Component in the Initiation of Somatic Embryogenesis}


Stress has been proposed for some time as being an important component of SE (Dudits et al. 1991). The first signal perceived by cells destined to become somatic embryos relates to the wounding that accompanies excision of the tissue or isolation of the cells. In M. truncatula, there are many stress-related proteins associated with SE (Imin et al. 2004). A number of these proteins are differentially expressed between regenerators and non-regenerators (Imin et al. 2005).

\subsection{Reactive Oxygen Species}

One of the earliest responses to wounding, and indeed many other abiotic and biotic stresses, is increased production of reactive oxygen species (ROS) at the site of stress, the so-called 'oxidative burst' (OrozcoCardenas and Ryan 1999). ROS, including superoxide and hydroxyl radicals and hydrogen peroxide $\left(\mathrm{H}_{2} \mathrm{O}_{2}\right)$ are produced as byproducts of oxygen metabolism (occurring in organelles, the cytosol, plasma membrane and apoplast) and can cause serious oxidative damage to the cell. However, it is increasingly recognized that ROS are important signalling molecules involved in plant development and environmental perception (Noctor 2006). Furthermore, ROS, particularly $\mathrm{H}_{2} \mathrm{O}_{2}$, function in lignification and oxidative cross-linking of the cell wall, control of cell growth, destruction (oxidation) of microbial pathogens and PCD/hypersensitive response (Dangl and Jones 2001; Gechev and Hille 2005).

Thus, ROS are produced by cultured explants in response to wounding. Indeed, staining explants with 3,3-diamidinobenzidine (DAB) reveals continual production of $\mathrm{H}_{2} \mathrm{O}_{2}$ in callus tissue during culture, although importantly, not in somatic embryos that form on the callus (N.A. Saeed, M.B. Sheahan and R.J. Rose, unpublished data). Moreover, culturing explants in the presence of diphenyleneiodonium (DPI), an inhibitor of flavoprotein-dependent ROS production, prevents the re-initiation of cell division in M. truncatula, Arabidopsis and tobacco leaf explants, indicating a critical role for ROS in explant regeneration (N.A. Saeed, M.B. Sheahan and R.J. Rose, unpublished data). In addition, it is known that oxidative stress causes plants cells to acquire a less differentiated state (Pasternak et al. 2002) and that oxidative stress enhances auxin-dependent cell cycle reactivation (Pasternak et al. 2005). Although ROS initially promote dedifferentiation and re-initiation of cell division, an inability to control levels of ROS 
may be a causal factor in recalcitrance of some species to undergo SE. Plants possess an arsenal of smallmolecule antioxidants (ascorbate, glutathione, and tocopherol) and antioxidant enzymes (including superoxide dismutases, peroxidases and catalase) and in cultured tobacco protoplasts, up-regulation of the activities of superoxide dismutase, ascorbate peroxidase and glutathione reductase follows the oxidative burst, causing reduced forms of glutathione and ascorbate to predominate. Significantly, this change does not occur in non-totipotent cells and appears necessary for the expression of totipotency (Papadakis et al. 2001).

The nature of downstream events involved in wound-induced ROS signalling remain unclear. However, they may involve direct interaction between ROS and redox sensitive transcription factors such as NPR1 (Mou et al. 2003), MAPK signalling cascades (Kovtun et al. 2000) or modification of thiol residues on proteins such as protein tyrosine phosphatases or glutathione peroxidases (Gupta and Luan 2003, Miao et al. 2006). ROS signalling may also be sensed via the level of small-molecule antioxidants such as glutathione. Indeed, progression from the $G_{1}$ to $S$ phases of the cell cycle requires adequate levels of reduced glutathione which may influence, in turn, the expression or activity of A-type cyclins or the cyclin dependent kinase inhibitor, CKI, respectively (Vernoux et al. 2000). Undoubtedly, manifestation of stress signalling involves cross-talk between hormonal and ROS signalling pathways and there exists substantial evidence linking auxin, abscisic acid, ethylene, jasmonic and salicylic acid signalling pathways with ROS signalling (Desikan et al. 2005).

Thus, ROS signalling appears critical to cellular reprogramming and re-initiation of the cell cycle. However, ROS also appear to be important for subsequent development of somatic embryos. Hence, $\mathrm{H}_{2} \mathrm{O}_{2}$ stimulates $\mathrm{SE}$ in Lycium barbarum (Cui et al. 1999; Kairong et al. 2002), glutathione redox state influences meristem development in Picea glauca SE (Stasolla et al. 2004; Belmonte et al. 2005; Belmonte and Stasolla 2007), while regions of somatic embryo formation are marked by high expression levels of an $\mathrm{H}_{2} \mathrm{O}_{2}$-producing oxalate oxidase in wheat (Caliskan et al. 2004). The effects of ROS on somatic embryo maturation may be mediated by its effects on cell walls that prevent cell expansion and cell-cell separation, thus promoting an 'embryogenically competent' microenvironment (Caliskan et al. 2004; Belmonte and Stasolla 2007). 


\subsection{Stress-Related Hormone Signalling}

In our recent study in M. truncatula (Mantiri et al. 2008), where SE is induced by auxin and cytokinin, it was shown that the stress-related hormone, ethylene, is synthesised within the first $24 \mathrm{~h}$ of initiating culture. Moreover, inhibitors of ethylene perception or biosynthesis prevent SE and expression of the ethylene response transcription factor (ERF), MtSERF1, a member of the AP2/ERF superfamily essential for SE (Mantiri et al. 2008). Knockdown of MtSERF1 expression by RNAi results in almost total suppression of SE. The expression of MtSERF1 is not only dependent on ethylene, but also auxin and cytokinin. Furthermore, the MtSERF1 promoter contains ethylene and auxin response elements and cytokinin-responsive ARR motifs. These data start to provide a molecular basis for the integration of stress and auxin/cytokinin-dependent signalling in SE.

Another stress-related hormone, abscisic acid (ABA), in certain systems can initiate SE (Nishiwaki et al. 2000). ABA can also promote SE induced by auxin and cytokinin in M. truncatula (Nolan and Rose 1998 ), so taken together with the ROS and the MtSERF1 data, these may be a signalling web that is likely to be similar, but subtly different, to other areas of plant development (Beveridge et al. 2007).

Existing evidence provides strong support for the involvement of stress in SE. As discussed in the next section, auxin is the key player in the SE paradigm and indeed 2,4-D, perhaps the most commonly used auxin, has been suggested to promote SE because of its herbicidal properties (Pasternak et al. 2002). Other auxins, however, can substitute for 2,4-D. So, while 2,4-D may add to the stress response, it is more likely to be acting to derepress genes in line with current evidence for auxin action (Rose and Nolan 2006).

\section{Hormones and the Initiation of Somatic Embryogenesis}


Classically, auxin has been considered the key player in the induction of SE and the formation of somatic embryos. As understanding of the mode of auxin action and the regulation of its transport increases (Friml et al. 2003; Tan et al. 2007) so too does evidence that auxin is the central player in regulation of plant (and somatic embryo) growth and development (Beveridge et al. 2007). The early work of Halperin showed that high concentrations of 2,4-D could produce PEMs from cultured petioles (in a medium containing reduced nitrogen) and somatic embryos were produced when transferred to liquid medium with no or low auxin. It was essential that the auxin concentration be lowered for SE to occur. Though the carrot system has served as the model for SE, there were always some difficulties in studying the activation events in SE, given the proembryogenic nature of the suspension culture (Dudits et al.1991).

The advent of model plants such as Arabidopsis and M. truncatula (Rose and Nolan 2006) has, to a degree, lessened the role of the carrot system in SE studies. Nevertheless, it provides an important perspective to SE (Mordhorst et al. 1997) and the work with the SERK1 gene in carrot ushered in a more concerted effort into the molecular biology of SE. With a luciferase reporter gene for cell tracking, it was shown that SERK is expressed in single cells that develop into somatic embryos and in carrot acted as a marker of cells competent for SE (Schmidt et al. 1997). SERK1, when over-expressed in Arabidopsis, is able to stimulate SE (Hecht et al. 2001). In M. truncatula the MtSERK1 gene is rapidly induced by auxin in cultured leaf explants and its expression is associated with both SE (SE requires auxin plus cytokinin in M. truncatula) and root morphogenesis. The extensive data now available on SERK (Rose and Nolan 2006 ) is consistent with an important role for SERK1 in SE competency, although it appears to have a broader role in differentiation as well (Nolan et al. 2003; Kwaaitaal and de Vries 2007).

Investigations into the homeobox gene, WUSCHEL (WUS), have also served to link SE to hormonal activation of specific developmental genes. WUS encodes a transcription factor that regulates the stem cell population in the shoot meristem. Over-expression in Arabidopsis formed embryo-like structures and it was suggested that WUS acted as both a meristem and embryo organiser (Zuo et al. 2002). Other work by Gallois et al. (2004) has shown in Arabidopsis that ectopic expression of WUS in roots could induce shoot organogenesis (low auxin) or SE (high auxin). An important consequence of this work is the concept that genes directing stem cell identity can reprogram somatic cells, with the direction 
of developmental change dependent on additional cues. Unpublished data of the authors in M. truncatula shows rapid induction of WUS expression. These data have been interpreted to suggest that genes involved with maintenance of pluripotent stem cells in meristems may have a role in inducing totipotent stem cells in culture. This has been included in the model shown in Fig. 3.

\section{Induction of SE by Over-Expression of Leafy Cotyledon Transcription Factors and their Relationship to SE induction and Repression - the GA Connection}

A framework is emerging of how stress and hormones can induce the activation of specific genes that can form stem cells capable of initiating the embryogenic pathway. Several transcription factors can induce SE independent of hormones, raising a number of questions in relation to the mechanism of SE. A connection between these different transcription factors is emerging in some cases, for example, the leafy cotyledon (LEC) group of transcription factors, required for SE in Arabidopsis, have an interesting connection to GA and ABA. LEC2 when over-expressed induces both SE and the MADS transcription factor AGL15 (Braybrook et al. 2006). Ectopic expression of AGL15 promotes somatic embryo formation in Arabidopsis (Harding et al. 2003). Further evidence indicates that AGL15 acts by targeting the GA2-oxidase, AtGA2ox6, which catabolises biologically active GA. This decrease in biologically active GA causes increased SE, while addition of $\mathrm{GA}_{3}$ causes a decrease in SE (Wang et al. 2004). A possible explanation for this effect lies with the pickle ( $p k l)$ mutant of Arabidopsis. The pkl mutant, so named because of its abnormal root phenotype, when cultured in the absence of plant hormones generates callus-like growth and forms somatic embryos on roots (Ogas et al. 1997). Wild-type roots do not produce callus or somatic embryos when cultured under the same conditions as the pkl roots. The surprising observation is that GA suppresses the pkl phenotype. The $P K L$ gene has been cloned (Ogas et al. 1999) and encodes a CHD3 protein linked to chromatin remodelling (component of a histone deacetylase complex). The PKL gene also appears to be necessary for the repression of LEC1 (Ogas et al. 1999; Rider et al. 2003). 
Thus, AGL15 and PKL investigations reveal a GA-modulated pathway that represses embryonic identity. It is essential to prevent inappropriate embryo formation as germination and subsequent plant development occurs. This repression is happening in parallel to the GA activation of postembryonic development in Arabidopsis. In principle, this is similar to the situation shown by Haerizadeh et al. (2006), who reported the repression of germ cell-specific genes in somatic cells. Results of GA-related studies imply that it is necessary to ensure GA-repression is derepressed before the SE induction pathway can be initiated.

\section{ABA, Stress and GA}

As discussed above, ABA can stimulate or induce SE in some systems (Nolan and Rose 1998; Nishiwaki et al. 2000) and as ABA and GA act antagonistically in germination (Henderson et al. 2004) it might be that the ABA effect on SE works through antagonising the GA effect. However, Henderson et al. (2004) found that ABA only had a small effect on the penetrance of the pkl phenotype. The authors postulated that PKL might regulate a subset of GA-dependent responses. Gazzarrini et al. (2004) have shown FUSA, a LEC transcription factor required for SE, is up-regulated by ABA and down-regulated by GA.

Overall, there is some coherency in these data which emphasise the need to have an SE repression system. The stress-related hormone ABA may well exert part of its action by contributing to overriding this repression.

\section{Soluble Signals and Cell -Cell Interactions that Promote SE in Suspension Cultures}

One observation frequently made in cultured cells, not discussed thus far, is the dependence of SE on cell density. Many compounds, whose concentration can vary with cell density, are released into the medium and affect SE. For example, carrot SE does not proceed at high density due to the release and build-up of 4-hydroxyphenol (Kobayashi et al. 2000). Conversely, conditioned medium factors such as 
phytosulfokine peptides can stimulate cell division (although not SE directly) in cultures of suboptimal density (Matsubayashi and Sakagami 1996).

\subsection{Secreted Proteins that Influence SE}

Some proteins affecting SE progression, such as trypsin inhibitor, are produced by both embryogenic and non-embryogenic carrot cultures, but only secreted by embryogenic cultures, thereby preventing degradation of proteins necessary for progression through SE (Quiroz-Figueroa et al. 2006). The majority of protein secreted into the medium, however, is glycoprotein (Quiroz-Figueroa et al. 2006), most notably AGPs, believed to have important roles in cell-cell interaction and signalling. The importance of AGPs in cell fate determination and in regulating passage through SE is highlighted by tight temporal and spatial regulation of AGP expression in the plant. In carrot cell cultures, a characteristic group of AGPs are secreted into the medium, the composition of which changes with time (Quiroz-Figueroa et al. 2006). These AGPs likely have a structural role. However, that AGP effects (enhancement or reduction in frequency of SE) exerted at nanomolar concentrations also suggests a signalling role. Interestingly, AGPs can contain GlcNAc and Glc residues, sensitive to cleavage by chitinases (van Hengel et al. 2001). AGPs treated with chitinase produce oligosaccharides, which are more active than AGPs in promoting SE (reviewed in Quiroz-Figueroa et al. 2006). Indeed, addition of EP3 chitinase to temperature-sensitive ts11 carrot cells is capable of rescuing the defective SE phenotype (Mordhorst et al. 1997). Thus, chitinase-modified AGPs are extracellular matrix molecules able to control plant cell fate (van Hengel et al. 2001). It has been suggested that these signals are indicative of cell-cell communication and hence the importance of these molecules.

\subsection{AGP Signalling in SE: Mechanisms and Interactions between Signalling Pathways}

Experiments in several species indicate that chitinases tend not to be expressed in cells of the embryo proper, but rather surrounding cells, providing evidence for the importance of intercellular 
communication in SE and is reminiscent of the endosperm-embryo relationship in zygotic embryogenesis (Wiweger et al. 2003). In Picea abies cultures, removal of plant growth regulators up-regulates expression of Chia4-Pa chitinase. Chia4-Pa stimulates PCD and promotes the PEM to somatic embryo transition (Wiweger et al. 2003). The presence of JIM13-reactive AGPs, a marker for cells undergoing PCD in maize and zinnia xylem transdifferentiation, on PEMs in P. abies provides further evidence to suggest that AGP signalling invokes PCD (Filonova et al. 2000). Thus, AGP signalling likely interacts with an integrated proliferation-PCD control system to regulate SE (Filonova et al. 2000, MajewskaSawka and Nothnagel 2000).

While soluble signals are undoubtedly important in suspension cultures, it does not necessarily mean that SE from tissue explants depends on the same signals, although clearly the cells that form somatic embryos are part of a stem cell niche dependent on the surrounding cells. It is becoming clear that cell wall related signalling cascades interact with hormonal and stress-signalling pathways invoked during SE. It is of interest in this regard to note that auxin deprivation (often used to promote PEM to somatic embryo transition) in tobacco BY2 suspension cultures results in a 2-fold increase in AGP secretion and a 4-fold increase in JIM13 reactivity (Winicur et al. 1998). Perturbation of cell walls can

signal stress responses. For example, aggregation of AGPs with Yariv reagent produces an expression profile most similar to wounding, leads to down-regulation of GA signalling and up-regulation of defence-related genes, while inhibition of cellulose synthesis results in increased production of ethylene and jasmonates (Ellis et al. 2002; Guan and Nothnagel 2004; Mashiguchi et al. 2008). Interestingly, AGPs are cross-linked by $\mathrm{H}_{2} \mathrm{O}_{2}$ and wounding in planta, providing credibility to the hypothesis that stress, hormonal and cell wall signalling interact in SE (Kjellbom et al. 1997). In Medicago ethylenedependent transcription factors are required for SE induced by auxin plus cytokinin.

\subsection{Cell-Cell Interaction and Relevance to SE in Suspension Cultures}

In carrot and other systems, researchers have noted the loss of embryogenic competence typically results in a reduction in the size of cell clusters that would normally form somatic embryos (Satoh 1998). 
Indeed, close observations reveal tighter contact between cells of embryogenic callus than between cells of non-embryogenic callus. Thus, loss of embryogenic competence is associated with a loosening of intercellular attachment, suggesting close attachment is necessary for SE in these culture systems (Satoh 1998). Moreover, in P. abies, PEMs readily develop in somatic embryos, whereas single cells (densely cytoplasmic or vacuolated), made by fractionation of crude suspensions, do not (Filonova et al. 2000). This fact demonstrates the obligate requirement for cell-cell interaction in some SE systems. Changes in cell-cell interaction over the course of SE are reflected in, and likely caused by, changes in cell wall composition. For example, pectin comprises a substantially larger proportion of the cell wall in somatic embryos than it does in plantlets regenerated from these embryos (Yeo et al. 1998). Furthermore, hemicelluloses display a transient increase in 5- and 3,5-linked arabinose during embryogenesis (Yeo et al. 1998). Notably, embryogenic cultures have significantly higher levels of neutral sugars like arabinose and xylose than do non-embryogenic cultures (Satoh 1998; Yeo et al. 1998). Neutral sugars are believed to play an important role in intercellular attachment and might act by bridging hemicellulose and pectin molecules (Satoh 1998). One gene product identified as critical for intercellular attachment is C-ESE1 from carrot (Takahata et al. 2004). The C-ESE1 gene is strongly up-regulated after depletion of 2,4-D from the medium and expressed specifically in the primordial cells of somatic embryos. Co-suppression of C-ESE1 expression leads to small cell clusters with weak intercellular attachment, thus delaying SE (Takahata et al. 2004). Observation of control and C-ESE1 co-suppressed cells by scanning electron microscopy reveals smooth cell surfaces of C-ESE1 co-suppressed cells, which also release large amounts of cell wall polysaccharide into the medium. Thus, C-ESE1 appears to play a role in polysaccharide deposition, in turn important for cell-cell attachment and SE. Notably, control of cell-cell interaction also appears important for SE progression in explant based systems, such as that of coconut (Verdeil et al. 2001).

\section{The Development Program after SE induction}


This discussion has focused on what is known about the biology of SE induction and the different threads of evidence from a range of culture systems. The tacit assumption is that once SE is induced there is an asymmetric division, albeit with the development fate of the cell that would contribute to the root pole and the suspensor in the zygotic embryo having a more variable history. This latter point is likely one reason for the variable nature of SE. However, once SE initiates, the developmental program is thought to be similar to zygotic embryogenesis, being a primary reason for the adoption of SE as a useful experimental system to understand zygotic embryogenesis. The defining feature of SE, set out in an important review by Zimmerman (1993), is the reprogramming of a somatic cell. Zimmerman's review emphasised that the ability to produce large quantities of embryos at different developmental stages was a distinct advantage in embryogenesis investigations. Zimmerman's validation of SE relied on gene expression data available at that time. Developments since 1993 have revealed the power of genomics, mutants and model organisms, particularly Arabidopsis (Fehér et al. 2003), but also Medicago (Rose and Nolan 2006). As pointed out by Fehér et al. (2003), research on the Arabidopsis embryogenesis mutants have provided insights into SE. However, there have been the discoveries of SERK and SERF genes from SE studies that are also expressed in zygotic embryogenesis. The reality now is that our understanding of embryogenesis benefits from comparisons between zygotic and SE. While there are likely some gene expression changes that reflect the different environments under which the embryos develop, the accumulated evidence suggests overwhelmingly similar developmental programs (Zimmerman 1993; Dodeman et al. 1997; Mantiri et al. 2008).

\section{Concluding Remarks and a Model Based on Studies in Medicago truncatula}

A model which provides a framework for our understanding and future work is shown in Fig 3. While it is based on experience with M. truncatula it draws conceptually from Arabidopsis and the wider literature discussed in this chapter. It is known that ROS are rapidly induced when tissue is excised and placed into culture and that ethylene is essential for SE. It is feasible that both ROS and auxin contribute to the induction of ethylene biosynthesis genes. ROS has been reported to promote auxin-induced 
ethylene production in mungbean hypocotyls (Song et al. 2007). It is also suggested that WUS is an important early player requiring cytokinins (our unpublished data). WUS, which has been postulated to be an embryo organiser (Zuo et al. 2002), is likely contributing to the production of stem cells similarly to as it does in the shoot meristem in planta. There is some evidence, as discussed earlier, that auxindependent SERK expression is indicative of cells primed for SE and commencing to differentiate. MtSERF1 expression is initiated after SERK expression. MtSERF1 is essential for SE. Based on physiological experiments and putative promoter binding sites, there is evidence that MtSERF1 expression requires cytokinin, auxin, ethylene and WUS (Mantiri et al. 2008). MtSERF1 may interconnect the stress and hormone signalling pathways. Based on the Arabidopsis studies discussed, it is assumed that the SE pathway is derepressed, involving an AGL15 dependent pathway, and the genes we have discussed are able to initiate the SE pathway.

\section{SE and Biotechnology}

The immense body of work on SE (more than 400 papers in the past 10 years) has arisen largely in response to the modern era of biotechnology and molecular biology. SE facilitates transformation for many species and, unless the floral dip procedures used in Arabidopsis or other in planta procedures can be developed for other species, SE remains a key component of many transformation protocols (organogenesis is the other regeneration pathway). The SE transformation protocols require the gene to be inserted into the somatic cell followed by regeneration via SE. The gene insertion is mostly by Agrobacterium, but can involve other methods such as microprojectiles.

The cloning of desirable genotypes using SE can be an advantage in high value plants such as in forestry, where it is a practicable propagation procedure (Sutton 2002), or in horticulture (Bunn et al. 2007), or with crops like potato (Seabrook and Douglass 2001). Greater knowledge may enable SE to be applied more efficiently and more broadly to encompass more species. Embryo production from nonzygotic cells in anther and isolated microspore culture in the production of doubled haploids has become important in breeding programs (Hosp et al. 2007). As pointed out in the introduction, an 
understanding of SE will also facilitate an understanding of apomixis. Illuminating how apomixis is induced remains a goal of both fundamental and applied plant research. The ability to produce seed with identical genotype to the parent would provide new plant breeding strategies, particularly with hybrid crops. SE falls under the umbrella of regeneration biology and an understanding of this reprogramming process remains an important biological question (Vogel 2005). Elucidating the mechanisms of SE will contribute to a fuller understanding of plant development.

\section{Acknowledgements}

Work in the authors' laboratory has been supported by an ARC Centre of Excellence Grant to the University of Newcastle Node of the ARC Centre of Excellence for Integrative Legume Research, to RJR (Grant CEO348212). 


\section{References}

Ammirato PV (1983) Embryogenesis. In: Evans DA, Sharp WR, Ammirato PV, Yamada Y (eds) Handbook of plant cell culture, Vol 1, Techniques in propagation and breeding. MacMilllan, New York, pp 82-123

Araújo SS, Duque ASRLA, Santos DMMF, Fevereiro MPS (2004) An efficient transformation method to regenerate a high number of transgenic plants using a new embryogenic line of Medicago truncatula cv. Jemalong. Plant Cell Tiss Organ Cult 78:123-131

Bäurle I, Smith L, Baulcombe DC, Dean C (2007) Widespread role for the flowering-time regulators FCA and FPA in RNA-mediated chromatin silencing. Science 318:109-112

Belmonte MF, Stasolla C (2007) Applications of DL-buthionine-[S,R]-sulfoximine deplete cellular glutathione and improve white spruce (Picea glauca) somatic embryo development. Plant Cell Rep 26:517-523

Belmonte MF, Donald G, Reid DM, Yeung EC and Stasolla C (2005) Alterations of the glutathione redox state improve apical meristem structure and somatic embryo quality in white spruce (Picea glauca). J Exp Bot 56:2355-2364

Bender J (2004) Chromatin-based silencing mechanisms. Curr Opin Plant Biol 7:521-526

Beveridge CA, Mathesius U, Rose RJ, Gresshoff PM (2007) Common regulatory themes in meristem development and whole plant homeostasis. Curr Opin Plant Biol 10:44-51

Bingham ET, Hurley LV, Kaatz DM, Saunders JW (1975) Breeding alfalfa which regenerates from callus tissue in culture. Crop Sci 15:719-721

Blervacq AS, Dubois T, Dubois J, Vassern J (1995) First divisions of somatic embryogenic cells in Cichorium hybrid '474'. Protoplasma 186:163-168

Braybrook SA, Stone SL, Park S, Bui AQ, Le BH, Fischer RL, Goldberg RB, Harada JJ (2006) Genes directly regulated by LEAFY COTYLEDON2 provide insight into the control of embryo maturation and somatic embryogenesis. Proc Natl Acad Sci USA 103:3468-3473 
Bunn E, Turner S, Panaia M, Dixon KW (2007) The contribution of in vitro technology and cryogenic storage to conservation of indigenous plants. Aust J Bot 55:345-355

Caliskan M, Turet M, Cuming AC (2004) Formation of wheat (Triticum aestivum L.) embryogenic callus involves peroxide-generating germin-like oxalate oxidase. Planta 219:132-140

Chandler JW, Cole M, Flier A, Grewe B, Werr W (2007) The AP2 transcription factors DORNRÖSCHEN and DORNRÖSCHEN-LIKE redundantly control Arabidopsis embryo patterning via interaction with PHAVOLUTA. Development 134:1653-1662

Cui KR, Xing GS, Liu XM, Xing GM and Wang YF (1999) Effect of hydrogen peroxide on somatic embryogenesis of Lycium barbarum L. Plant Sci 146:9-16

Dangl JL, Jones JD (2001) Plant pathogens and integrated defence responses to infection. Nature $411: 826-833$

Desikan R, Hancock J, Neill S (2005) Reactive oxygen species as signalling molecules. In: Smirnoff N (ed) Antioxidant and reactive oxygen species in plants. Blackwell Publishing, Oxford, pp 169196

Dijak M, Smith DL, Wilson TJ, Brown DC (1986) Stimulation of direct embryogenesis from mesophyll protoplasts of Medicago sativa. Plant Cell Rep 5:468-470

Dodeman VL, Ducreux G, Kreis M (1997) Zygotic embryogenesis versus somatic embryogenesis. J Exp Bot 48:1493-1509

Dudits D, Bögre L, Györgyey J (1991) Molecular and cellular approaches to the analysis of plant embryo development from somatic cells in vitro. J Cell Sci 99:475-484

Ellis C, Karafyllidis I, Wasternack C, Turner JG (2002) The Arabidopsis mutant cev1 links cell wall signalling to jasmonate and ethylene responses. Plant Cell 14:1557-1566

Fehér A, Pasternak TP, Dudits D (2003) Transition of somatic plant cells to an embryogenic state. Plant Cell Tiss Organ Cult 74:201-228

Filonova LH, Bozhkov PV, von Arnold S (2000) Developmental pathway of somatic embryogenesis in Picea abies as revealed by time-lapse tracking. J Exp Bot 51:249-264 
Friml J, Vieten A, Weijers D, Schwarz H, Haqmann T, Offringa R, Jürgens G (2003) Efflux-dependent auxin gradients establish the apical-basal axis of Arabidopsis. Nature 426:147-153

Gallois JL, Nora FR, Mizukami Y, Sablowski R (2004) WUSCHEL induces shoot stem cell activity and developmental plasticity in the root meristem. Genes Dev 18:375-380

Garcês HMP, Champagne CEM, Townsley BT, Park S, Malhó R, Pedroso MC, Harada JJ, Sinha NR (2007) Evolution of asexual reproduction in leaves of the genus Kalanchoë. Proc. Natl Acad Sci USA 104:15578-15583

Gazzarrini S, Tsuchiya Y, Lumba S, OkamotoM, McCourt P (2004) The transcription factor FUSCA3 controls developmental timing in Arabidopsis through the hormones gibberellin and abscisic acid. Dev Cell 7:373-385

Gechev TS, Hille J (2005) Hydrogen peroxide as a signal controlling plant programmed cell death. J Cell Biol 168:17-20

Geldner N, Anders N, Wolters H, Keicher J, Kornberger W, Muller P, Delbarre A, Ueda T, Nakano A, Jürgens G (2003) The Arabidopsis GNOM ARF-GEF mediates endosomal recycling, auxin transport, and auxin-dependent plant growth. Cell 112:219-230

Goubet F, Misrahi A, Park SK, Zhang Z, Twell D, Dupree P (2003) AtCSLA7, a cellulose synthase-like putative glycosyltransferase, is important for pollen tube growth and embryogenesis in Arabidopsis. Plant Physiol 131:547-557

Guan Y, Nothnagel EA (2004) Binding of arabinogalactan proteins by Yariv phenylglycoside triggers wound-like responses in Arabidopsis cell cultures. Plant Physiol 135:1346-1366

Gupta R, Luan S (2003) Redox control of protein tyrosine phosphatases and mitogen-activated protein kinases in plants. Plant Physiol 132:1149-1152

Guzzo F, Baldan, B, Mariani P, Lo Schiavo F, Terzi M (1994) Studies on the origin of totipotent cells in explants of Daucus carota L. J Exp Bot 45:1427-1432

Haccius B (1978) Question of unicellular origin of non-zygotic embryos in callus cultures. Phytomorphology 28:74-81 
Haecker A, Groß-Hardt R, Geiges B, Sarkar A, Breuninger H, Herrmann M, Laux T (2004) Expression dynamics of WOX genes mark cell fate decisions during early embryonic patterning in Arabidopsis thaliana. Development 131:657-688

Haerizadeh F, Singh MB, Bhalla PL (2006) Transcriptional repression distinguishes somatic from germ cell lineages in a plant. Science 313:496-499

Hall Q, Cannon MC (2002) The cell wall hydroxyproline-rich glycoprotein RSH is essential for normal embryo development in Arabidopsis. Plant Cell 14:1161-1172

Halperin W (1966) Alternative morphogenetic events in cell suspensions. Am J Bot 53:443-453

Harding EW, Tang WN, Nichols KW, Fernandez DE, Perry SE (2003) Expression and maintenance of embryogenic potential is enhanced through constitutive expression of AGAMOUS-Like 15. Plant Physiol 133:653-663

Hecht V, Vielle-Calzada J-P, Hartog MV, Schmidt EDL, Boutilier K, Grossniklaus U, de Vries SC (2001) The Arabidopsis SOMATIC EMBRYOGENESIS RECEPTOR KINASE 1 gene is expressed in developing ovules and embryos and enhances embryogenic competence in culture. Plant Physiol 127:803-816

Henderson IR, Jacobsen SE (2007) Epigenetic inheritance in plants. Nature 447:418-424

Henderson JT, Li H-C, Rider SD, Mordhorst AP, Romero-Severson J, Cheng J-C, Robey J, Sung ZR, de Vries SC, Olgas J (2004) Pickle acts throughout the plant to repress expression of embryonic traits and may play a role in gibberellin-dependent responses. Plant Physiol 134:995-1005

Hoffman B, Trinh TH, Leung J, Kondorosi A, Kondorosi E (1997) A new Medicago truncatula line with superior in vitro regeneration, transformation, and symbiotic properties isolated through cell culture selection. Mol Plant-Microbe Interact 10:307-315

Hosp J, de Faria Maraschin S, Touraev A, Boutilier K (2007) Functional genomics of microspore embryogenesis. Euphytica 158:275-285

Ikeda-Iwai M, Umehara M, Satoh S, Kamada H (2003) Stress-induced somatic embryogenesis in vegetative tissues of Arabidopsis thaliana. Plant J 34:107-114 
Imin N, De Jong F, Mathesius U, van Noorden G, Saeed NA, Wang X.-D, Rose RJ, Rolfe, BG (2004) Proteome reference maps of Medicago truncatula embryogenic cell cultures generated from single protoplasts. Proteomics 4:1883-1896

Imin N, Nizamidin M, Daniher D, Nolan KE, Rose RJ, Rolfe BG (2005) Proteomic analysis of somatic embryogenesis in Medicago truncatula. Explant cultures grown under 6-benzylaminopurine and 1-naphthaleneacetic acid treatments. Plant Physiol 137:1250-1260

Ingram GC (2004) Between the sheets: inter-cell-layer communication in plant development. Phil Trans R Soc Lond B Biol Sci 359:891-906

Jenik PD, Barton MK (2005) Surge and destroy: the role of auxin in plant embryogenesis. Development $132: 3577-3585$

Kairong C, Ji L, Gengmei X, Jianlong L, Lihong W, Yafu W (2002) Effect of hydrogen peroxide on synthesis of proteins during somatic embryogenesis in Lycium barbarum. Plant Cell Tiss Organ Cult 68:187-193

Kamada H, Ishikawa K, Saga H, Harada H (1993) Induction of somatic embryogenesis in carrot by osmotic stress. Plant Tiss Cult Lett 10:38-44

Kepinski S, Leyser O (2003) An axis of auxin. Nature 426:132-135

Kielly GA, Bowley SR (1992) Genetic control of somatic embryogenesis in alfalfa. Genome 35:474-477

Kjellbom P, Snogerup L, Stohr C, Reuzeau C, McCabe PF, Pennell RI (1997) Oxidative cross-linking of plasma membrane arabinogalactan proteins. Plant J 12:1189-1196

Kobayashi T, Higashi K, Sasaki K, Asami T, Yoshida S, Kamada H (2000) Purification from conditioned medium and chemical identification of a factor that inhibits somatic embryogenesis in carrot. Plant Cell Physiol 41:268-273

Koltunow AM, Grossniklaus U (2003) Apomixis: A developmental perspective. Annu Rev Plant Biol $54: 547-574$

Kovtun Y, Chiu WL, Tena G, Sheen J (2000) Functional analysis of oxidative stress-activated mitogenactivated protein kinase cascade in plants. Proc Natl Acad Sci USA 97:2940-2945 
Kwaaitaal MACJ, de Vries SC (2007) The SERK1 gene is expressed in procambium and immature vascular cells. J Exp Bot 58:2887-2896

Loiseau J, Michaux-Ferrière N, Le Denunff Y (1998) Histology of somatic embryogenesis in pea. Plant Physiol Biochem 36:683-687

Lu C-Y, Vasil IK (1985) Histology of somatic embryogenesis in Panicum maximum (Guinea grass). Am J Bot 72:1908-1913

Majewska-Sawka A, Nothnagel EA (2000) The multiple roles of arabinogalactan proteins in plant development. Plant Physiol 122:3-10

Mantiri FR, Kurdyukov S, Lohar DP, Sharapova N, Saeed NA, VandenBosch KA, Rose RJ (2008) The transcription factor MtSERF1 of the ERF subfamily identified by transcriptional profiling is required for somatic embryogenesis induced by auxin plus cytokinin in Medicago truncatula. Plant Physiol 146:1622-1636

Mashiguchi K, Urakami E, Hasegawa M, Sanmiya K, Matsumoto I, Yamaguchi I, Asami T, Suzuki Y (2008) Defense-related signaling by interaction of arabinogalactan proteins and $\beta$-glucosyl Yariv reagent inhibits gibberellin signaling in barley aleurone cells. Plant Cell Physiol 49:178-190

Matsubayashi Y, Sakagami Y (1996) Phytosulfokine, sulfated peptides that induce the proliferation of single mesophyll cells of Asparagus officinalis L. Proc Natl Acad Sci USA 93:7623-7627

Mayer U, Büttner G, Jürgens G (1993) Apical-basal pattern formation in the Arabidopsis embryo: studies on the role of the gnom gene. Development 117:149-162

McCabe PF, Valentine TA, Forsberg LS, Pennell RI (1997) Soluble signals from carrots identified at the cell wall establish a developmental pathway in carrot. Plant Cell 9:2225-2241

Miao Y, Lv D, Wang P, Wang X-C, Chen J, Miao C, Song C-P (2006) An Arabidopsis glutathione peroxidase functions as both a redox transducer and a scavenger in abscisic acid and drought stress responses. Plant Cell 18:2749-2766

Mordhorst AP, Toonen MAJ, de Vries SC (1997) Plant embryogenesis. Crit Rev Plant Sci 16:535-576

Mou Z, Fan W, Dong X (2003) Inducers of plant systemic acquired resistance regulate NPR1 function through redox changes. Cell 113:935-944 
Müller B, Sheen J (2007) Advances in cytokinin signaling. Science 318:68-69

Nishiwaki M, Fujino K, Koda Y, Masuda K, Kikuta Y (2000) Somatic embryogenesis induced by the simple application of abscisic acid. Planta 211:756-759

Noctor G (2006) Metabolic signalling in defence and stress: the central roles of soluble redox couples. Plant Cell Environ 29:409-425

Nolan KE, Rose RJ (1998) Plant regeneration from cultured Medicago truncatula with particular reference to abscisic acid and light treatments. Aust J Bot 46:151-160

Nolan KE, Irwanto RR, Rose RJ (2003) Auxin up-regulates MtSERK1 expression in both Medicago truncatula root-forming and embryogenic cultures. Plant Physiol 133:218-230

Nolan KE, Rose RJ, Gorst JE (1989) Regeneration of Medicago truncatula from tissue culture: increased somatic embryogenesis from regenerated plants. Plant Cell Rep 25:278-281

Nolan KE, Saeed NA, Rose RJ (2006) The stress kinase gene MtSK1 in Medicago truncatula with particular reference to somatic embryogenesis. Plant Cell Rep 25:711-722

Ogas J, Cheng J-C, Sung ZR, Somerville C (1997) Cellular differentiation regulated by gibberellin in the Arabidopsis thaliana pickle mutant. Science 277:91-94

Ogas J, Kaufmann S, Henderson J, Somerville C (1999) Pickle is a CHD3 chromatin-remodeling factor that regulates the transition from embryonic to vegetative development in Arabidopsis. Proc Natl Acad Sci USA 96:13839-13844

Orozco-Cardenas M, Ryan CA (1999) Hydrogen peroxide is generated systemically in plant leaves by wounding and systemin via the octadecanoid pathway. Proc Natl Acad Sci USA 96:6553-6557

Papadakis AK, Siminis CI, Roubelakis-Angelakis KA (2001) Reduced activity of antioxidant machinery is correlated with suppression of totipotency in plant protoplasts. Plant Physiol 126:434-444

Pasternak TP, Prinsen E, Ayaydin F, Miskolczi P, Potters G, Asard H, Van Onckelen HA, Dudits D, Fehér A (2002) The role of auxin, $\mathrm{pH}$, and stress in the activation of embryogenic cell division in leaf protoplast-derived cells of alfalfa. Plant Physiol 129:1807-1819 
Pasternak T, Potters G, Caubergs R, Jansen MAK (2005) Complementary interactions between oxidative stress and auxins control plant growth responses at plant, organ, and cellular level. J Exp Bot $56: 1991-2001$

Pennell RI, Janniche L, Kjellbom P, Scofield GN, Peart JM, Roberts K (1991) Developmental regulation of a plasma membrane arabinogalactan protein epitope in oilseed rape flowers. Plant Cell 3:1317-1326

Quiroz-Figueroa F, Rojas-Herrera R, Galaz-Avalos R, Loyola-Vargas VC (2006) Embryo production through somatic embryogenesis can be used to study cell differentiation in plants. Plant Cell Tiss Organ Cult 86:285-301

Reinert J (1958) Morphogenese und ihre kontrolle an gewebekulturen aus carotten. Naturwissenchaften $45: 344-345$

Rider SD, Henderson JT, Jerome RE, Edenberg HJ, Romero-Severson J, Ogas J (2003) Coordinate repression of regulators of embryonic identity by PICKLE during germination in Arabidopsis. Plant J 35:33-43

Rose RJ (2004) Somatic embryogenesis in plants. In: Goodman RM (ed) Encyclopedia of plant and crop science, Maecel Dekker Inc, New York, pp 1165-1168

Rose RJ, Nolan KE (1995) Regeneration of Medicago truncatula from protoplasts isolated from kanamycin-sensitive and kanamycin-resistant plants. Plant Cell Rep 14:349-354

Rose RJ, Nolan KE (2006) Genetic regulation of somatic embryogenesis with particular reference to Arabidopsis thaliana and Medicago truncatula. In Vitro Cell Dev Biol-Plant 42:473-481

Rose RJ, Nolan KE, Bicego L (1999) The development of the highly regenerable seed line Jemalong 2 HA for transformation of Medicago truncatula - Implications for regenerability via somatic embryogenesis. J Plant Physiol 155:788-791

Rose RJ, Wang X-D, Nolan KE, Rolfe BG (2006) Root meristems in Medicago truncatula tissue culture arise from vascular-derived procambial-like cells in a process regulated by ethylene. J Exp Bot $57: 2227-2235$ 
Sagare AP, Suhasini K, Krishnamurthy KV (1995) Histology of somatic embryo initiation and development in chickpea (Cicer arietinum L.). Plant Sci 109:87-93

Santos D, Fevereiro P (2002) Loss of DNA methylation affects somatic embryogenesis in Medicago truncatula. Plant Cell Tiss Organ Cult 70:155-161

Satoh S (1998) Functions of the cell wall in the interactions of plant cells: Analysis using carrot cultured cells. Plant Cell Physiol 39:361-368

Scheres B, Benfey PN (1999) Asymmetric cell division in plants. Annu Rev Plant Physiol Plant Mol Biol 50:505-537

Schmidt EDL, Guzzo F, Toonen MAJ, de Vries SC (1997) A leucine-rich repeat containing receptor-like kinase marks somatic plant cells competent to form embryos. Development 124:2049-2062

Schwendiman J, Pannetier C, Michaux-Ferriere N (1988) Histology of somatic embryogenesis from leaf explants of the oil palm Elais guineensis. Ann Bot 62:43-52

Seabrook JEA, Douglass LK (2001) Somatic embryogenesis on various potato tissues from a range of genotypes and ploidy levels. Plant Cell Rep 20:175-182

Sharma SK, Millam S (2004) Somatic embryogenesis in Solanum tuberosum L.: a histological examination of key developmental stages. Plant Cell Rep 23:115-119

Somleva MN, Schmidt EDL, de Vries SC (2000) Embryogenic cells in Dactylis glomerata L. (Poaceae) explants identified by cell tracking and by SERK expression. Plant Cell Rep 19:718-726

Song YJ, Joo JH, Ryu HY, Lee JS, Bae YS, Nam KH (2007) Reactive oxygen species mediate IAAinduced ethylene production in mungbean (Vigna radiata L.) hypocotyls. J Plant Biol 50:18-23

Souter M, Lindsey K (2000) Polarity and signalling in plant embryogenesis. J Exp Bot 51:971-983

Stasolla C, Belmonte MF, van Zyl L, Craig DL, Liu W, Yeung EC, Sederoff RR (2004) The effect of reduced glutathione on morphology and gene expression of white spruce (Picea glauca) somatic embryos. J Exp Bot 55:695-709

Steward FC, Mapes O, Smith J (1958) Growth and organised development of cultured cells 1. Growth and division of freely suspended cells. Am J Bot 45:693-703 
Steward FC, Mapes MO, Kent AE, Holsten RD (1964) Growth and development of cultured plant cells. Science 143:20-27

Sutton B (2002) Commercial delivery of genetic improvement to conifer plantations using somatic embryogenesis. Ann For Sci 59:657-661

Takahata K, Takeuchi M, Fujita M, Azuma J, Kamada H, Sato F (2004) Isolation of putative glycoprotein gene from early somatic embryo of carrot and its possible involvement in somatic embryo development. Plant Cell Physiol 45:1658-1668

Tan X, Calderon-Villalobos LIA, Sharon M, Zheng C, Robinson CV, Estelle M, Zheng N (2007) Mechanism of auxin perception by the TIRI ubiquitin ligase. Nature 446:640-622

Touraev A, Vicente O, Heberle-Bors E (1997) Initiation of microspore embryogenesis by stress. Trends Plant Sci 2:297-302

van Hengel AJ, Tadesse Z, Immerzeel P, Schols H, van Kammen A, de Vries SC (2001) NAcetylglucosamine and glucosamine-containing arabinogalactan proteins control somatic embryogenesis. Plant Physiol 125:1880-1890

Vasil IK (1988) Progress in the regeneration and genetic manipulation of cereal crops. Bio/Technology 6:397-402

Verdeil JL, Hocher V, Huet C, Grosdemange F, Escoute J, Ferriere N, Nicole M (2001) Ultrastructural changes in coconut calli associated with the acquisition of embryogenic competence. Ann Bot $88: 9-18$

Vernoux T, Wilson RC, Seeley KA, Reichheld J-P, Muroy S, Brown S, Maughan SC, Cobbett CS, Van Montagu M, Inze D, May MJ, Sung ZR (2000) The ROOT MERISTEMLESS1/CADMIUM SENSITIVE2 gene defines a glutathione-dependent pathway involved in initiation and maintenance of cell division during postembryonic root development. Plant Cell 12:97-110

Vogel G (2005) How does a single somatic cell become a whole plant. Science 309:86

Wang H, Caruso LV, Downie AB, Perry SE (2004) The embryo MADS domain protein AGAMOUSLike 15 directly regulates expression of a gene encoding an enzyme involved in gibberellin metabolism. Plant Cell 16:1206-1219 
Williams EG, Maheswaran G (1986) Somatic embryogenesis: factors influencing coordinated behaviour of cells as an embryogenic group. Ann Bot 57:443-462

Winicur ZM, Feng Zhang G, Andrew Staehelin L (1998) Auxin deprivation induces synchronous golgi differentiation in suspension-cultured tobacco BY-2 cells. Plant Physiol 117:501-513

Wiweger M, Farbos I, Ingouff M, Lagercrantz U, Von Arnold S (2003) Expression of Chia4-Pa chitinase genes during somatic and zygotic embryo development in Norway spruce (Picea abies): similarities and differences between gymnosperm and angiosperm class IV chitinases. J Exp Bot $54: 2691-2699$

Yamamoto N, Kobayashi H, Togashi T, Mori Y, Kikuchi K, Kuriyama K, Tokuji Y (2005) Formation of embryogenic cell clumps from carrot epidermal cells is suppressed by 5-azacytidine, a DNA methylation inhibitor. J Plant Physiol 162:47-54

Yeo U-D, Kohmura H, Nakagawa N, Sakurai N (1998) Quantitative and qualitative changes of cell wall polysaccharides during somatic embryogenesis and plantlet development of asparagus (Asparagus officinalis L.). Plant Cell Physiol 39:607-614

Zimmerman JL (1993) Somatic embryogenesis: a model for early development in higher plants. Plant Cell 5:1411-1423

Zuo JR, Niu Q-W, Frugis G, Chua NH (2002) The WUSCHEL gene promotes vegetative-to-embryonic transition in Arabidopsis. Plant J 30:349-359 


\section{Figure Legends}

Fig. 1. The main conceptual components to consider for an understanding of the mechanism of somatic embryogenesis.

Fig. 2. Totipotent cells are produced from procambium or differentiated cells such as mesophyll cells and initiate embryogenesis, or may divide a number of times to form a PEM before initiating embryogenesis. (A) Totipotent cells are produced from procambium or differentiated cells, such as mesophyll cells, and initiate embryogenesis, or may divide a number of times to form a PEM before initiating embryogenesis. (B) Section through a Medicago truncatula leaf explant initiating somatic embryogenesis. The globular stage somatic embryos have been initiated near the surface on the adaxial side of the leaf quite separate from the vascular tissue and arise from dedifferentiated mesophyll cells. M, dedifferentiating mesophyll cells; VT, vascular tissue; arrowheads, somatic embryos at different stages of development. Bar $=100 \mu \mathrm{m}$.

Fig.3. A model for the induction of somatic embryogenesis and the development of the heart-stage embryo from Medicago truncatula mesophyll cells, drawing on research from the authors' laboratory and the literature discussed in this review. 
Fig. 1.

Explant + Stress + Hormone(s)

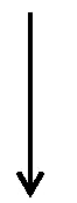

Redetermination

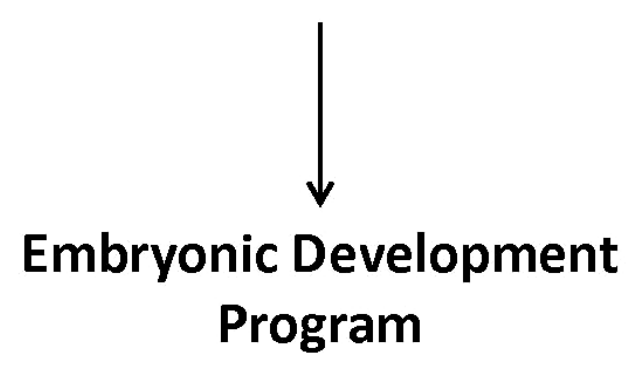


Fig. 2

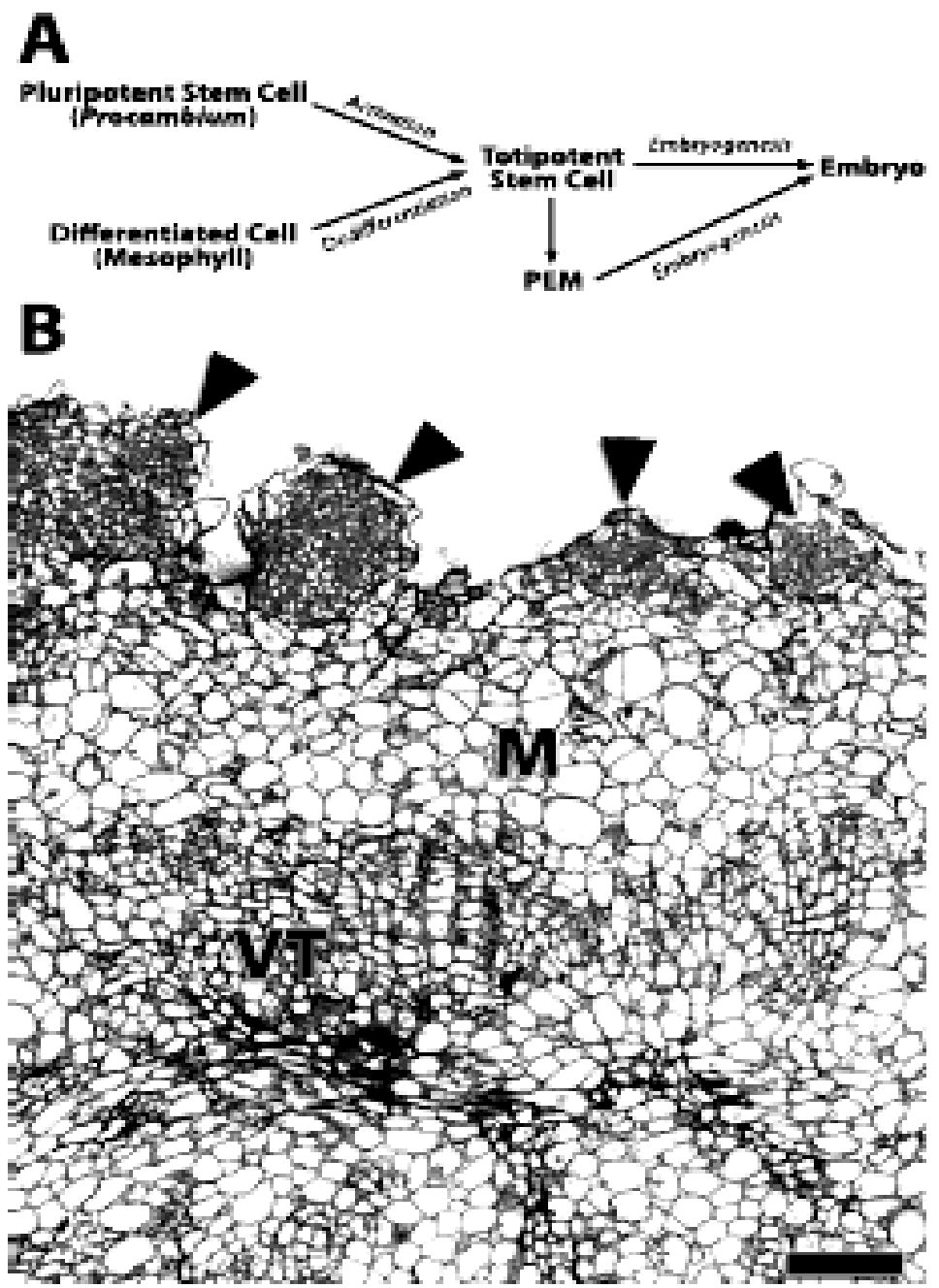


Fig. 3
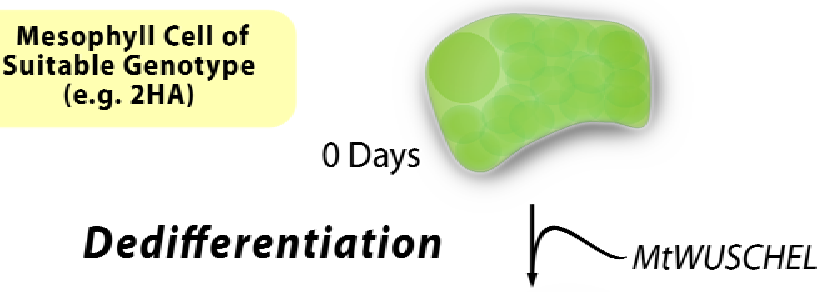
Auxin \&
Cytokinin

ROS Generation

(e.g. $\mathrm{H}_{2} \mathrm{O}_{2}$ )

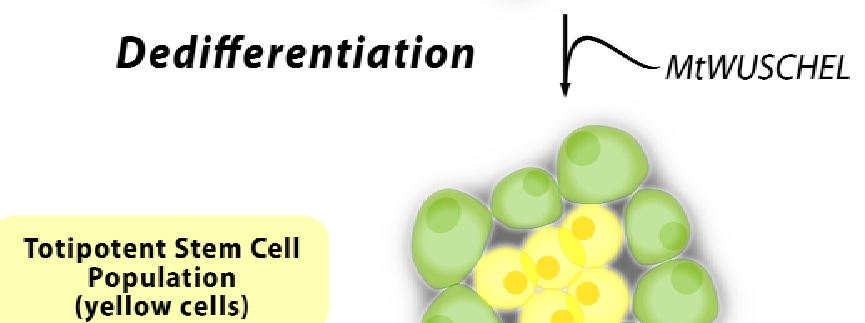

Ethylene

Biosynthesis

\section{Cell Cycle Genes \\ (Proliferation)}

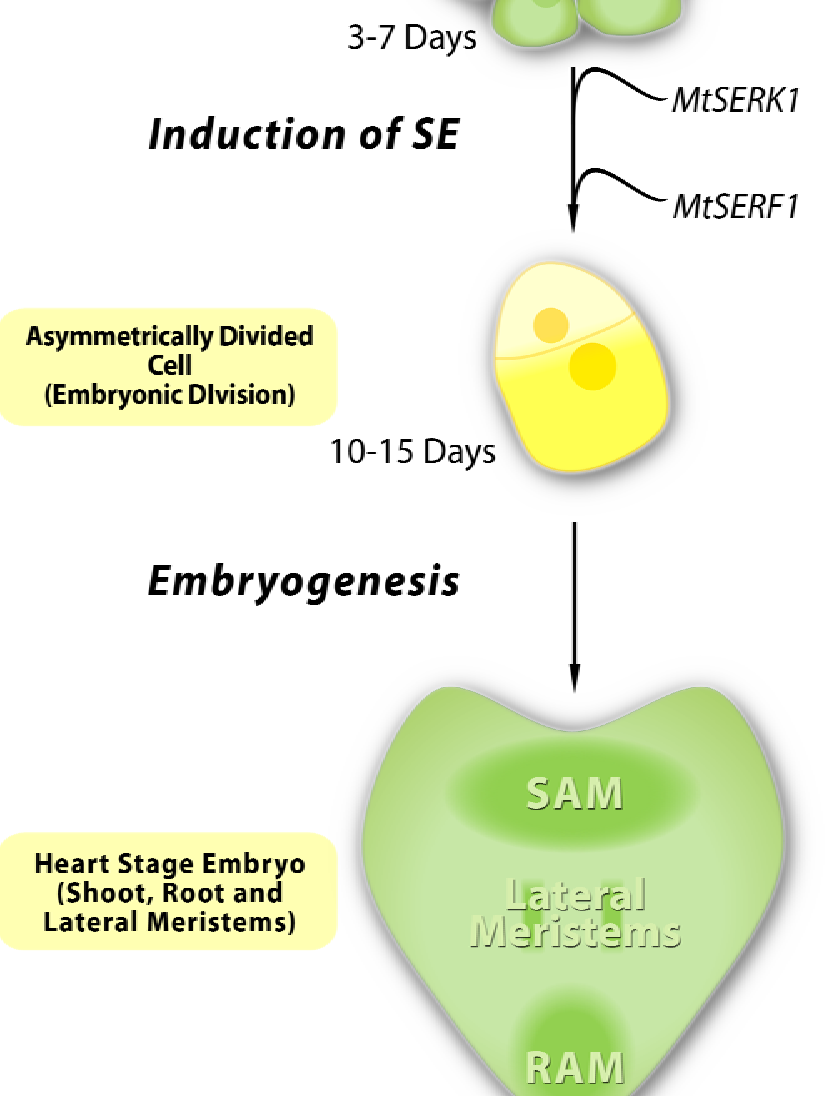

Embryonic Patterning Genes

28-35 Days 